\title{
The predictors of Enhanced Recovery After Surgery utilization and practice variations in elective colorectal surgery: a provincial survey
}

\author{
Jeremy E. Springer, MD, MSc \\ Aristithes G. Doumouras, \\ MD, MPH \\ Sara Lethbridge \\ Shawn Forbes, MD, MSc \\ Cagla Eskicioglu, MD, MSc
}

Accepted Dec. 5, 2019

\section{Correspondence to:}

C. Eskicioglu

St. Joseph's Healthcare Hamilton

Mary Grace Wing, Rm G836

50 Charlton Ave E

Hamilton ON L8N 4A6

eskicio@mcmaster.ca

DOI: $10.1503 /$ cjs.009419

\begin{abstract}
Background: Enhanced Recovery After Surgery (ERAS) protocols use evidencebased perioperative practices that reduce morbidity and length of stay and improve patient satisfaction. ERAS is considered standard of care; however, utilization remains low and substantial practice variation exists. The aim of this study was to pragmatically characterize variation in colorectal surgery practice and identify predictors of ERÁS utilization.

Methods: A survey of general surgeons identified using the Ontario College of Physicians and Surgeons database was conducted. Information on basic demographic characteristics, utilization of ERAS and predictors of ERAS implementation was collected. Nine ERAS behaviours were analyzed. Multivariable analysis was used to determine effects of demographic, hospital and surgeon covariates on ERAS utilization.
\end{abstract}

Results: Seven hundred and ninety-seven general surgeons were invited to participate in the survey, and 235 general surgeons representing 84 Ontario hospitals responded (30\% response rate). Surgeons practising in academic settings and in large community hospitals represented $30 \%$ and $47 \%$ of the respondents, respectively. A total of $20 \%$ of the respondents used all 9 ERAS behaviours consistently. Rates of diet advancement on postoperative day 0 , intravenous fluid restriction and having catheter and line procedures were significantly higher among respondents who adhered to ERAS protocols than among those who did not $(74 \%$ v. $54 \%, p=0.004 ; 92 \%$ v. $80 \%$, $p=0.01$; and $91 \%$ v. $41 \%, p<0.001$, respectively). Respondents from academic settings reported practising nearly 1 more ERAS behaviour than those from small community hospitals (odds ratio [OR] $0.86,95 \%$ confidence interval [CI] 0.42 to $1.31, p<$ $0.001)$. Multivariable analysis demonstrated that colorectal fellowship training or exposure to ERAS during training did not significantly affect ERAS behaviour utilization (OR $0.32,95 \% \mathrm{CI}-0.31$ to $0.94, p=0.16$; OR $0.28,95 \% \mathrm{CI}-0.26$ to $0.82, p=$ 0.16 , respectively).

Conclusion: Substantial practice variation in colorectal surgery still exists. Individual ERAS principles are commonly followed; however, ERAS behaviours are not widely formalized into hospital protocols.

Contexte : Les protocoles de récupération optimisée après une chirurgie (ou ERAS, pour enhanced recovery after surgery) utilisent des pratiques périopératoires fondées sur des données probantes pour réduire la morbidité, abréger la durée des séjours hospitaliers et améliorer la satisfaction des patients. Les protocoles ERAS sont considérés comme une norme thérapeutique; toutefois, leur utilisation reste faible et on note une importante variation dans leur application. Le but de cette étude était de caractériser dans les faits les variations des pratiques en chirurgie colorectale et d'identifier les prédicteurs de l'utilisation des protocoles ERAS.

Méthodes : Un sondage a été effectué auprès des chirurgiens généraux de la base de données du Collège des médecins et chirurgiens de l'Ontario. On a recueilli des données sur les caractéristiques démographiques de base, l'utilisation des protocoles ERAS et les prédicteurs de leur déploiement. Neuf pratiques ERAS ont été analysées. L'analyse multivariée a permis de déterminer les effets des covariables démographiques, hospitalières et celles des chirurgiens sur le recours aux protocoles ERAS.

Résultats : Nous avons invité 797 chirurgiens généraux à participer au sondage, et 235 d'entre eux représentant 84 hôpitaux ontariens y ont répondu (taux de réponse $30 \%$ ). Les chirurgiens des établissements universitaires et des grands hôpitaux communautaires ont représenté respectivement $30 \%$ et $47 \%$ des répondants. En tout, $20 \%$ des répondants ont déclaré appliquer les 9 pratiques ERAS de manière constante. 
L'alimentation précoce au Jour 0 postopératoire, la restriction des liquides intraveineux et les directives concernant les cathéters et les sondes étaient significativement mieux observées chez les répondants qui adhéraient aux protocoles ERAS que chez ceux qui n'y adhéraient pas $(74 \%$ c. $54 \%, p=0,004 ; 92 \%$ c. $80 \%$, $p=0,01$; et $91 \%$ c. $41 \%, p<$ 0,001 , respectivement). Les répondants des milieux universitaires ont indiqué appliquer près de 1 comportement ERAS de plus que ceux des petits hôpitaux communautaires (rapport des cotes [RC] 0,86, intervalle de confiance [IC] de $95 \%$ de 0,42 à 1,31, $p<$ 0,001). L'analyse multivariée a démontré que la spécialisation en chirurgie colorectale ou l'exposition aux protocoles ERAS en cours de formation n'ont pas significativement influé sur l'application des pratiques ERAS (RC 0,32, IC de $95 \%$ de $-0,31$ à 0,94, $p=$ 0,16 ; RC 0,28, IC de $95 \%$ de $-0,26$ à $0,82, p=0,16$, respectivement).

Conclusion : On continue d'observer une importante variation des pratiques en chirurgie colorectale. Les principes ERAS individuels sont généralement suivis, mais ils ne sont pas formellement intégrés aux protocoles hospitaliers.

$\mathbf{T}$ here has been considerable advancement over the last 2 decades in the perioperative and postoperative care of patients who undergo elective colorectal surgery. Earlier practice included features such as postoperative bowel rest, graded diet advancement and generous intravenous fluid replacement; however, ongoing research and improvements in our understanding of postoperative physiology have changed this surgical dogma. Colorectal surgery carries a particularly high complication rate; however, a substantial amount of research has focused on optimizing several perioperative factors to reduce this risk. The development of Enhanced Recovery After Surgery (ERAS) programs has substantially changed the management of patients who undergo elective colorectal surgery and has become standard of care. ${ }^{1,2}$ The fundamental principle of ERAS programs is to use specific perioperative and postoperative interventions to reduce the overall physiologic stress related to surgery and reestablish homeostasis during the perioperative period. Numerous studies have clearly demonstrated improved postoperative recovery and outcomes with ERAS programs following colorectal surgery. ${ }^{3-10}$

Despite our extensive knowledge regarding ERAS, previous audits of colorectal surgery practices have shown that perioperative care and postoperative care are substantially different from evidence-based practice. Furthermore, these studies have identified that there is substantial room for both educating clinicians and increasing awareness of updated practice recommendations such as ERAS. ${ }^{11-14}$ To date, no large-scale multicentre studies have specifically evaluated ERAS uptake and barriers to implementation, but it has been shown that the simple introduction of an ERAS protocol to a hospital organization is not sufficient to ensure adequate implementation. ${ }^{15}$ A single-institution qualitative study by Pearsall and colleagues did identify barriers to uptake; these included limited patient education and difficulties with buy-in by the multidisciplinary team. ${ }^{16}$ It is difficult to identify with certainty how colorectal surgical care is provided on a large scale in either public or private health systems, because the current body of literature is based on data that were obtained from sub- specialized colorectal surgeons or academic surgeons or were collected before ERAS programs became popular. In the present study, our primary purpose was to pragmatically identify the existing perioperative practice patterns and their association with current ERAS guidelines, among all general surgeons performing elective colon and rectal surgery in Ontario, Canada. The ultimate goal of this research is to identify variations in perioperative colorectal surgical care to inform and improve health care delivery in a large publicly funded health system.

\section{Methods}

\section{Survey design and sample}

A survey was created with a multidisciplinary team including surgeons, surgical residents, research assistants and surgical nurses. ${ }^{17}$ The 33 -question survey was divided into 4 sections: demographics, specific ERAS perioperative details, details regarding utilization of ERAS protocols, and additional comments (see Appendix 1, available at canjsurg.ca/009419-a1). A consent form detailed the purpose of the survey, provided instructions for completing the survey and stipulated that surgeons who did not practise colorectal surgery should complete only the demographics section. A pilot survey was distributed to 5 general surgeons in Ontario; the final survey incorporated the feedback from this pilot along with further modifications from the study investigators.

The College of Physicians and Surgeons of Ontario (CPSO) database was used to identify potential participants for the survey and to gather basic demographic information. All general surgeons registered with the CPSO in 2018 were invited to participate in the survey. The initial data search included all general surgeons registered with the CPSO. Data details included basic demographic information, such as name, sex, practice address, specialty type and hospital privileges. (The only information from the database that was used in the analysis was the respondents' mailing address; all other demographic data used in the analysis were collected from the survey.) Duplicates and 
registered CPSO members who did not meet the inclusion criteria (i.e., members who had obtained further subspecialty training in fields such as vascular, thoracic or pediatric surgery) were excluded.

The survey was distributed by postal mail to all actively practising general surgeons who performed colon or rectal resections in Ontario in 3 individual rounds over 3 months beginning in November 2017, and participants also had the option of completing it online. Responses from each participant were counted only once, even if they completed both the paper- and web-based versions of the survey. Each survey package contained a consent form, the survey, a stamped return envelope and the research team's contact information. Participants were removed from subsequent rounds of mailouts if they had returned a survey previously. The survey was anonymized by unique identifiers. This study received approval from the Hamilton Integrated Research Ethics Board.

\section{Statistical analysis}

When applicable, descriptive statistics were used to analyze the characteristics of the study population. When comparing the use of formal ERAS protocols, we conducted a univariable analysis using $t$ tests or $\chi^{2}$ tests for demographic, hospital and surgeon differences. A multivariable logistic regression was performed with the demographic and hospital factors as fixed effects. Analysis included weighted adjustment between variables. Odds ratios with $95 \%$ confidence intervals (CIs) were reported to determine the adjusted effects of the demographic and hospital covariates on the use of a formal ERAS program. Statistical significance was set at a $p$ value less than 0.05 , and data analysis was performed using Stata release 13.1 (StataCorp).

\section{Results}

The survey was distributed to 797 general surgeons. There were 235 respondents, for a response rate of $30 \%$; 84 hospitals across the province were represented. Table 1 presents the demographic characteristics of the respondents. The median age of respondents was 45 years (interquartile range 39-53 yr) and 69\% were male. Eighty-nine respondents (38\%) of respondents reported practising general surgery for over 15 years. One hundred and ten (47\%) worked in large community hospitals and $71(30 \%)$ worked in academic hospitals. Almost half (47\%) had performed between 10 and 29 colon or rectal resections in the previous year. Formal fellowship training in minimally invasive surgery had been obtained by 77 respondents (32\%), and $29(12 \%)$ reported having obtained formal fellowship training in colorectal surgery. Only 88 respondents (38\%) had been exposed to ERAS during either their residency or their fellowship training,

\begin{tabular}{|c|c|}
\hline Variable & $\begin{array}{l}\text { No. (\%) of respondents* } \\
\qquad n=235\end{array}$ \\
\hline Sex, female & 73 (31) \\
\hline Age, median (IQR) & 45 (39-53) \\
\hline \multicolumn{2}{|l|}{ No. of years in practice } \\
\hline$<5$ & $61(26)$ \\
\hline $5-10$ & $54(23)$ \\
\hline $11-15$ & $31(13)$ \\
\hline$>15$ & $89(38)$ \\
\hline \multicolumn{2}{|l|}{ Training details } \\
\hline MIS fellowship & $77(32)$ \\
\hline Colorectal fellowship & $29(12)$ \\
\hline ERAS experience & $88(38)$ \\
\hline \multicolumn{2}{|l|}{ Hospital type } \\
\hline Academic & $71(30)$ \\
\hline Small community ${ }^{\dagger}$ & $52(22)$ \\
\hline Large community $\ddagger$ & $110(47)$ \\
\hline \multicolumn{2}{|c|}{$\begin{array}{l}\text { No. of elective colorectal resections } \\
\text { performed in previous year }\end{array}$} \\
\hline$<10$ & $70(30)$ \\
\hline $10-29$ & $108(47)$ \\
\hline $30-49$ & $33(14)$ \\
\hline$\geq 50$ & $21(9)$ \\
\hline Formal ERAS protocol followed & $162(68)$ \\
\hline $\begin{array}{l}\text { ERAS = Enhanced Recovery after Sur } \\
\text { invasive surgery. } \\
\text { *Unless indicated otherwise. } \\
\text { †Hospital with }<100 \text { inpatient beds. } \\
\text { ‡Hospital with } \geq 100 \text { inpatient beds. }\end{array}$ & rtile range; $\mathrm{MIS}=$ minimally \\
\hline
\end{tabular}

and only 162 respondents (68\%) had incorporated a formal ERAS protocol in their practice.

Table 2 compares the perioperative practice behaviours of surgeons who adhere to formal ERAS programs and those who do not. This study did not specifically differentiate between elective and emergent colorectal operations. Utilization of formalized ERAS order sets was significantly higher among surgeons who reported following an ERAS protocol than among those who did not (94\% v. 26\%, $p<$ 0.001). Additionally, surgeons who follow ERAS protocols were signifcantly more likely to advance diet on postoperative day 0 , restrict intravenous fluids and have a protocol for catheters and lines than surgeons who do not follow ERAS protocols $(74 \%$ v. $54 \%, p=0.004 ; 92 \%$ v. $80 \%, p=$ 0.01 ; and $91 \%$ v. $41 \%, p<0.001$, respectively). Most respondents do not routinely leave postoperative nasogastric tubes, regardless of whether or not they use formal ERAS protocols; however $4 \%$ of the total cohort still routinely does.

Table 3 presents the results of a multivariable linear regression assessing surgeon characteristics and surgical practice variables and their respective effect on performing ERAS-related behaviours. Having a colorectal fellowship, having a fellowship in minimally invasive surgery or being exposed to ERAS during training did not have a significant 
Table 2. Comparison of perioperative practice behaviours of respondents who adhere to formal ERAS protocols and those who do not

\begin{tabular}{|c|c|c|c|c|}
\hline \multirow[b]{3}{*}{ ERAS variable } & \multicolumn{3}{|c|}{ No. (\%) of respondents* } & \multirow[b]{3}{*}{$p$ value } \\
\hline & \multicolumn{2}{|c|}{ Formal ERAS followed } & \multirow[b]{2}{*}{ Total } & \\
\hline & No & Yes & & \\
\hline Standard ERAS order set & $17(26)$ & $150(94)$ & $167(74)$ & $<0.001$ \\
\hline \multicolumn{5}{|l|}{ ERAS behaviours } \\
\hline Limits NGT use & $63(97)$ & $160(99)$ & $223(99)$ & 0.34 \\
\hline Diet on postoperative day 0 & $35(54)$ & $119(74)$ & $154(68)$ & 0.004 \\
\hline Preoperative rehabilitation & $31(49)$ & $103(65)$ & $134(60)$ & 0.032 \\
\hline Restrictive fluid therapy & $51(80)$ & $148(92)$ & $199(88)$ & 0.01 \\
\hline Epidural anesthesia and narcotic reduction & $47(75)$ & $124(77)$ & $171(76)$ & 0.70 \\
\hline Balanced postoperative analgesia & $49(77)$ & $117(74)$ & $166(74)$ & 0.64 \\
\hline Early postoperative mobilization & $64(100)$ & $153(96)$ & $217(97)$ & 0.12 \\
\hline Standard catheter and lines protocol & $26(41)$ & $147(91)$ & $173(77)$ & $<0.001$ \\
\hline Immediate discharge when criteria met & $63(97)$ & $154(98)$ & $217(97)$ & 0.82 \\
\hline \multicolumn{5}{|c|}{$\begin{array}{l}\text { ERAS = Enhanced Recovery After Surgery; NGT = nasogastric tube. } \\
{ }^{*} \text { Owing to incomplete survey responses, the number of responses for individual questions ranged between } 223 \text { and } 227 \text {. A total of } \\
210 \text { respondents answered every survey question. }\end{array}$} \\
\hline
\end{tabular}

in a small community setting (OR $0.86,95 \%$ CI 0.42 to $1.31, p<0.001)$. Finally, having a standardized ERAS order set was the most important and significant factor influencing ERAS behaviours (OR 1.67, 95\% CI 1.16 to 2.2, $p<0.001)$.

Table 4 presents the results of a multivariable linear regression assessing surgeon and surgical practice predictors for having an ideal ERAS colorectal practice. The ideal ERAS practice consists of utilization of all 9 ERAS behaviours (detailed in Table 2). Overall, 20\% of respondents practised consistently with the 9 ERAS behaviours. Being female (OR 0.29, 95\% CI 0.07 to $0.71, p=0.019)$ and performing 10-29 colorectal resections per year (OR 4.77, 95\% CI 1.14 to $15.6, p=0.044$ ) were significantly associated with practising colorectal surgery with all 9 ERAS behaviours.

Despite variations in peri- and postoperative care following colorectal surgery and adherence to a formalized ERAS protocol, the mean number of ERAS behaviours practised by respondents was 7.02 (standard deviation 1.97) (Fig. 1), and when given a hypothetical patient undergoing a laparoscopic right hemicolectomy, the majority $(60 \%)$ would prepare their patient for an expected length of stay of 1-3 days.

\section{Discussion}

A growing body of literature has continued to demonstrate that ERAS programs in colorectal surgery improve postoperative outcomes, reduce complications and overall cost and generally accelerate postoperative recovery. ${ }^{5,8,18,19}$ The goal of this provincial survey was to determine the extent to which ERAS principles are being used across a large Canadian province and to determine if there are any specific surgeon or practice characteristics that influence their use. To our knowledge, this survey is unique because it pragmatically assessed ERAS utilization among surgeons practising colorectal surgery who have varying degrees of training and ERAS exposure and who practise in a diverse range of hospital settings (small community, large community and academic hospitals). The study achieved an overall response rate of $29.5 \%$, which is consistent with the response rates of similar studies using surveys of general surgeons. ${ }^{20}$ The major finding of the study is that despite the overwhelming evidence supporting ERAS utilization in colorectal surgery, nearly one-third of 
Table 4. Results of multivariable linear regression assessing the predictors of practising colorectal surgery in an ideal ERAS practice

\begin{tabular}{|c|c|c|}
\hline Variable & OR (95 \% Cl) & $p$ value \\
\hline Age & 0.98 (0.89 to 1.05$)$ & 0.56 \\
\hline Sex, female & $0.29(0.07$ to 0.71$)$ & 0.019 \\
\hline \multicolumn{3}{|l|}{ No. of years in practice ${ }^{*}$} \\
\hline $5-10$ & $1.31(0.26$ to 4.01$)$ & 0.96 \\
\hline $11-15$ & $2.62(0.26$ to 10.72$)$ & 0.58 \\
\hline$>15$ & $2.82(0.18$ to 13.07$)$ & 0.67 \\
\hline ERAS experience during training & 3.07 (0.53 to 10.52$)$ & 0.28 \\
\hline Colorectal fellowship & $3.89(0.64$ to 14.51$)$ & 0.19 \\
\hline MIS fellowship & 0.64 (0.17 to 1.66$)$ & 0.29 \\
\hline \multicolumn{3}{|l|}{$\begin{array}{l}\text { No. of elective colorectal } \\
\text { resections in previous yeart }\end{array}$} \\
\hline 10-29 & 4.77 (1.14 to 15.63$)$ & 0.044 \\
\hline $30-49$ & $2.29(0.26$ to 8.74$)$ & 0.63 \\
\hline$\geq 50$ & 7.57 (0.56 to 36.56$)$ & 0.17 \\
\hline \multicolumn{3}{|l|}{ Hospital typeł } \\
\hline Large community & $5.54(0.91$ to 18.29$)$ & 0.07 \\
\hline Academic & $2.98(0.86$ to 7.91$)$ & 0.10 \\
\hline Formal ERAS protocol followed & $3.15(0.61$ to 11.66$)$ & 0.26 \\
\hline Standardized ERAS order set & 7.31 (1.15 to 27.57$)$ & 0.041 \\
\hline \multicolumn{3}{|c|}{$\begin{array}{l}\mathrm{Cl}=\text { confidence interval; ERAS = Enhanced Recovery After Surgery; MIS = minimally } \\
\text { invasive surgery; } \mathrm{OR}=\text { odds ratio. } \\
{ }^{*} \text { Compared with }<5 \text { years in practice. } \\
\text { †Compared with }<10 \text { colorectal resections. } \\
\text { fCompared with small community hospitals ( }<100 \text { inpatient beds). }\end{array}$} \\
\hline
\end{tabular}

respondents still do not utilize formal ERAS protocols and only approximately $20 \%$ utilize all features of a standardized ERAS practice. Interestingly, despite not having formal ERAS protocols, several respondents reported using perioperative ERAS behaviours. Finally, this study has demonstrated using a multivariable logistic regression analysis that having standardized ERAS order sets and practising in a large academic centre are independently associated with the use of more ERAS behaviours.

Numerous single-institution and international surveys investigating ERAS protocols in colorectal surgery have demonstrated low uptake, utilization, adherence and wide practice variation among both surgeons and anesthesiologists. ${ }^{11,12,15,16,21}$ In a similar study of colorectal surgeons, Lassen and colleagues found that there was significant variation in perioperative care across several northern European countries. Specifically, the majority of Dutch surgeons used prophylactic nasogastric tubes until patients had a bowel movement and the majority of Scottish and Dutch surgeons would restrict diet advancement 1-2 and sometimes 3-4 days postoperatively. Furthermore, all countries lacked restrictive fluid strategies. ${ }^{12}$

There are several advantages to the present study, including its pragmatic nature, in that all general surgeons who perform the majority of colorectal resections in Ontario were invited to participate and more than 10 years have passed since the introduction of ERAS, allowing for more opportunity for the principles to be widely accepted. Additionally, to our knowledge this is the first study to spe- cifically analyze the variations in perioperative practice in colorectal surgery in Canada, and our findings clearly demonstrate that substantial variation still exists in perioperative practice in colorectal surgery. The analysis has also demonstrated that having formalized ERAS protocols significantly increases the rates of early diet advancement, judicious use of intravenous fluids and having a protocol for catheters and lines. The data demonstrate that even though 13 randomized trials have demonstrated no benefit of withholding enteral intake following gastrointestinal surgery, $2246 \%$ of respondents who do not have a formal ERAS protocol and $26.5 \%$ of those who do have a formal protocol still do not practise early enteral feeding following colorectal surgery. Interestingly, this study also demonstrated that use of other ERAS behaviours such as perioperative epidural use and narcotic reduction, balanced postoperative analgesia and early mobilization did not differ between respondents who follow formal ERAS protocols and those who do not. This finding is partially consistent with the results of Hannemann and colleagues, who demonstrated in a 2006 survey that most anesthesiologists continue to use epidurals and short-acting anesthetics in colorectal surgery; ${ }^{21}$ however, epidural analgesia has been shown in several studies to be superior to postoperative opioid analgesia ${ }^{23}$ and in some institutions it is considered standard of care regardless of whether or not the institution uses ERAS protocols.

To our knowledge, to date no study has specifically attempted to assess the relative contribution of each individual ERAS behaviour to postoperative outcomes; however, the present study has demonstrated that individual ERAS principles are widely used outside of formal ERAS protocols. Our results suggest that surgeons will essentially tailor ERAS strategies to produce personalized ERAS protocols. Further prospective studies are required to determine whether adherence to a formal ERAS protocol or just to the individual ERAS components translates into improved postoperative outcomes and whether there is an additive effect of these behaviours.

Another interesting result of this study is that despite the overwhelming evidence against the use of prophylactic nasogastric tube decompression following colorectal surgery, $4 \%$ of respondents, the majority of whom practise in community hospitals, still routinely leave postoperative nasogastric tubes. Previous early research has shown that decompression with prophylactic nasogastric tubes following laparotomy is not required in the majority of patients and is associated with increased morbidity and delayed return of gastrointestinal function, ${ }^{24}$ and several high-quality reviews and meta-analyses have confirmed this. ${ }^{25-27}$ In a 2006 multinational survey, Hasenberg and colleagues showed that routine nasogastric tube use following postoperative day 1 was limited in Austria and Germany; however, it was still performed by between 3\% and $13 \%$ of surgeons. ${ }^{14}$ In another multinational survey 


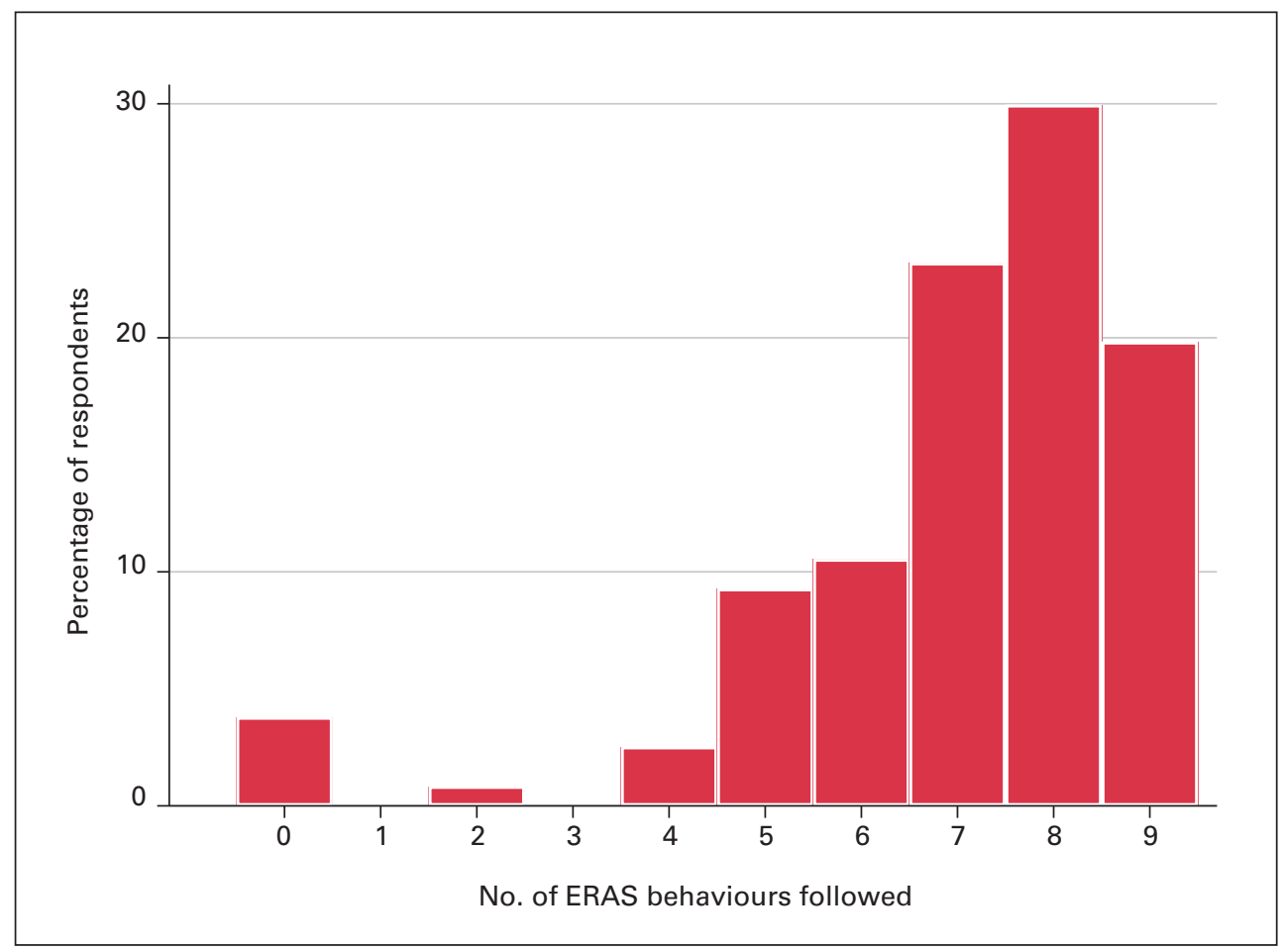

Fig. 1. Number of Enhanced Recovery After Surgery (ERAS) behaviours followed by survey respondents.

of 295 hospitals in the United States and Europe in 2006, Kehlet and colleagues showed that the majority of patients (mean 66\%) had a nasogastric tube postoperatively; however, the majority of the tubes were removed on postoperative day $1 .^{7}$

The present data, along with previous research, further demonstrate the lack of evidence-based practice in colorectal surgery, especially among surgeons practising in small community settings. This survey supports the need for improved education about and dissemination of ERAS principles.

To our knowledge, this is the first study to assess the effect of surgeon characteristics and practice details on the utilization of ERAS behaviours using a multivariable regression analysis. The analysis demonstrated that practising in an academic centre and having a standardized ERAS order set significantly increased the use of individual ERAS behaviours. Nearly $20 \%$ of respondents utilize all 9 ERAS behaviours consistently, and being female and performing 10-29 colorectal resections per year were statistically significant predictors of this.

There have been extensive efforts to improve the uptake of ERAS behaviours, including the development of the iERAS group based at the University of Toronto, which has the aim of increasing and facilitating utilization of ERAS protocols following colorectal surgery. For example, McLeod and colleagues used a specific strategy based on the knowledge-to-action cycle to implement an ERAS program at 15 academic hospitals in Ontario and initially demonstrated positive outcomes with uptake of the program in $2015 .^{28}$ In a recent update on these data, Aarts and colleagues assessed ERAS intervention compliance and demonstrated only a $40 \%$ compliance rate for postoperative interventions; they also found that compliance with all phases of the ERAS pathway only occurred for $20.1 \%$ of patients. ${ }^{3}$ Although these results suggest generally low uptake and compliance at the academic centres, in the present study, which was conducted on a larger scale and used a multivariable analysis adjusting for surgeon and practice variables, we found that patients are more likely to undergo formalized postoperative ERAS care if they have colorectal surgery at an academic centre.

Despite the demonstration that performance of 10-29 resections annually was a statistically significant predictor of increased ERAS use, we interpret the self-reported case volume data as being statistically equivalent. Accordingly, ERAS uptake is more related to the size and resources of the facility than to the volume of an individual surgeon. The specific reason for this is unclear; however, we have several hypotheses. It is possible that large academic institutions require a more streamlined approach to postoperative care and protocols because of the requirements associated with having a large pool of learners and allied health staff. It is also possible that academic centres, with their larger number of administrators, standardize the volumes of their surgeons to a greater degree than community hospitals do, or that academic surgeons are more receptive to recent evidence and more willing to change practice on the basis of the latest research.

Another interesting finding is the lack of association between ERAS utilization and exposure to ERAS during training, formal colorectal training or formal training in minimally invasive surgery. This unexpected finding could be explained by the fact that the median age of respondents was 45 years and therefore the majority of the respondents' surgical training predated the introduction and uptake of ERAS.

The study identified that the perioperative management of patients undergoing colorectal surgery in Ontario remains variable. There is a robust body of evidence demonstrating the benefits and improved outcomes associated 
with particular perioperative practice patterns, specifically the utilization of ERAS protocols in patients undergoing colorectal surgery. This study highlights the need for general surgeons in Ontario to evaluate their current practice and potentially update certain outdated habits. Additionally, this study provides an evidence-based resource for general surgeons wishing to initiate ERAS protocols at their local institution and begin discussions with hospital administrators about the cost savings associated with ERAS protocols following initial resource investment around ERAS implementation. ${ }^{29}$ The barriers to ERAS implementation and adherence identified in this study could provide surgeons and hospitals with the knowledge required to create implementation strategies.

\section{Limitations}

This study has several limitations that exist in all qualitative survey research; however, the study methods were previously validated in an analysis of the same survey population. ${ }^{17}$ The inherent biases that exist in all survey data due to the nature of data acquisition are difficult to control and therefore accepted. The concerns about overor underestimation of data are appreciated; however, previous studies examining survey response bias specifically for health care professionals have found that it is lower than for surveys of the general population. ${ }^{30,31}$ Further, owing to the nature of the data specifically measuring uptake of ERAS protocols, there is limited response bias because the data are not influenced by respondent opinion. Intraoperative anesthetic details such as intravenous fluid restriction and epidural anesthesia are not generally considered part of the surgeon's responsibility and therefore these data do not directly reflect surgeon preference; however, our results emphasize the requirement for a multidisciplinary approach to ERAS protocols. We did not differentiate between elective and emergent colorectal cases; however, because ERAS protocols are generally not used in the acute care surgical patient, the assumption is that respondents mainly provided data on their elective colorectal practice. The response rate of $29.5 \%$ may appear low, but it is considered average for surveys of surgeons ${ }^{20}$ and furthermore the results are generalizable to a larger population because they were obtained from the majority of hospitals across the province and the characteristics of the respondents were representative of the majority of the general surgeons in Ontario.

\section{Conclusion}

This survey of general surgeons practising colorectal surgery in Ontario has clearly shown that despite the development and demonstration of efficacy of ERAS and fasttrack surgery protocols more than 2.5 decades ago, there is still substantial variation in perioperative practice in colorectal surgery. The pragmatic and generalizable nature of the study is highlighted by the fact that the majority of the data were obtained from community general surgeons who perform the majority of colon and rectal resections in Ontario. This study highlights the fact that despite the vast amount of literature supporting the routine use of ERAS practices in colorectal surgery, perioperative practice varies widely, especially in small hospitals. Although one-third of respondents performing colorectal surgery do not adhere to formalized ERAS protocols, there is relatively high use of individual ERAS behaviours. Therefore, the assumption is either that clinicians only believe in aspects of ERAS perioperative care and consequently pick and choose various behaviours or that the formalization of ERAS pathways is a demanding process, requiring substantial resources, so surgeons choose to practise ERAS in an informal way. Regardless, further research is required to identify ways in which ERAS protocols can be used in all hospital settings where colorectal surgery is performed. This study provides an evidence-based resource for general surgeons wishing to initiate ERAS protocols at their local institution and begin discussions with hospital administrators to justify the cost and resource investment for ERAS implementation.

Affiliation: From the Department of Surgery, McMaster University, Hamilton, Ont.

Competing interests: None declared.

Funding: McMaster Surgical Associates Research Award provided the funding for this study.

Contributors: J. Springer, S. Lethbridge S. Forbes and C. Eskicioglu designed the study. J. Springer, S. Lethbridge and C. Eskicioglu acquired the data, which J. Springer, A. Doumouras, S. Forbes and C. Eskicioglu analyzed. J. Springer and C. Eskicioglu drafted the manuscript, which all authors critically revised. All authors gave final approval of the version to be published.

\section{References}

1. Donohoe CL, Nguyen M, Cook J, et al. Fast-track protocols in colorectal surgery. Surgeon 2011;9:95-103.

2. Gustafsson UO, Hausel J, Thorell A, et al. Adherence to the enhanced recovery after surgery protocol and outcomes after colorectal cancer surgery. Arch Surg 2011;146:571-7.

3. Aarts M-A, Rotstein OD, Pearsall EA, et al. Postoperative ERAS interventions have the greatest impact on optimal recovery. Ann Surg 2018;267:992-97.

4. Spanjersberg WR, Reurings J, Keus F, et al. Fast track surgery versus conventional recovery strategies for colorectal surgery. Cocbrane Database Syst Rev 2011 Feb 16;(2):CD007635.

5. Eskicioglu C, Forbes SS, Aarts M-A, et al. Enhanced recovery after surgery (ERAS) programs for patients having colorectal surgery: a meta-analysis of randomized trials. $\mathcal{F}$ Gastrointest Surg 2009;13:2321-9.

6. Varadhan KK, Neal KR, Dejong CHC, et al. The enhanced recovery after surgery (ERAS) pathway for patients undergoing major elective open colorectal surgery: a meta-analysis of randomized controlled trials. Clin Nutr 2010;29:434-40.

7. Kehlet H, Dahl JB. Anaesthesia, surgery, and challenges in postoperative recovery. Lancet 2003;362:1921-8. 
8. Wind J, Polle SW, Fung Kon Jin PHP, et al. Systematic review of enhanced recovery programmes in colonic surgery. Br 7 Surg 2006;93:800-9.

9. Basse L, Thorbøl JE, Løssl K, et al. Colonic surgery with accelerated rehabilitation or conventional care. Dis Colon Rectum 2004;47:271-7.

10. Jottard KJC, Van Berlo C, Jeuken L, et al. Changes in outcome during implementation of a fast-track colonic surgery project in a universityaffiliated general teaching hospital: advantages reached with ERAS over a 1-year period. Dig Surg 2008;25:335-8.

11. Kehlet H, Büchler MW, Beart Jr RW, et al. Care after colonic operation - Is it evidence-based? Results from a multinational survey in Europe and the United States. 7 Am Coll Surg 2006;202:45-54.

12. Lassen K, Hannemann P, Ljungqvist $\mathrm{O}$, et al. Patterns in current perioperative practice: survey of colorectal surgeons in five northern European countries. BM7 2005;330:1420-1.

13. Walter CJ, Smith A, Guillou P. Perceptions of the application of fast-track surgical principles by general surgeons. Ann R Coll Surg Engl 2006;88:191-5.

14. Hasenberg T, Keese M, Längle F, et al. "Fast-track" colonic surgery in Austria and Germany - results from the survey on patterns in current perioperative practice. Colorectal Dis. 2009;11:162-7.

15. Maessen J, Dejong CHC, Hausel J, et al. A protocol is not enough to implement an enhanced recovery programme for colorectal resection. Br 7 Surg 2007;94:224-31.

16. Pearsall EA, Meghji Z, Pitzul KB, et al. A qualitative study to understand the barriers and enablers in implementing an enhanced recovery after surgery program. Ann Surg 2015;261:92-6.

17. Springer JE, Doumouras AG, Lethbridge S, et al. A provincial assessment of the barriers and utilization of enhanced recovery after colorectal surgery. 7 Surg Res 2019;235:521-8.

18. Ljungqvist $\mathrm{O}, \mathrm{Scott} M$, Fearon KC. Enhanced recovery after surgery a review. JAMA Surg 2017;152:292-8.

19. Pritts TA, Nussbaum MS, Flesch LV, et al. Implementation of a clinical pathway decreases length of stay and cost for bowel resection. Ann Surg 1999;230:728-33.
20. Cunningham CT, Quan H, Hemmelgarn B, et al. Exploring physician specialist response rates to web-based surveys. BMC Med Res Methodol 2015;15:32.

21. Hannemann P, Lassen K, Hausel J, et al. Patterns in current anaesthesiological peri-operative practice for colonic resections: a survey in five northern-European countries. Acta Anaesthesiol Scand 2006;50:1152-60.

22. Andersen HK, Lewis SJ, Thomas S. Early enteral nutrition within $24 \mathrm{~h}$ of colorectal surgery versus later commencement of feeding for postoperative complications. Cochrane Database Syst Rev 2006;18:CD004080.

23. Block BM, Liu SS, Rowlingson AJ, et al. Efficacy of postoperative epidural analgesia: a meta-analysis. FAMA 2003;290:2455-63.

24. Cheadle WG, Vitale GC, Mackie CR, et al. Prophylactic postoperative nasogastric decompression. A prospective study of its requirement and the influence of cimetidine in 200 patients. Ann Surg 1985;202:361-6.

25. Cheatham ML, Chapman WC, Key SP, et al. A meta-analysis of selective versus routine nasogastric decompression after elective laparotomy. Ann Surg 1995;22 1:469-76, discussion 476-8.

26. Nelson R, Tse B, Edwards S. Systematic review of prophylactic nasogastric decompression after abdominal operations. Br 7 Surg 2005; 92:673-80.

27. Verma R, Nelson RL. Prophylactic nasogastric decompression after abdominal surgery. Cochrane Database Syst Rev 2007;2007(3):CD004929.

28. McLeod RS, Aarts M-A, Chung F, et al. Development of an enhanced recovery after surgery guideline and implementation strategy based on the knowledge-to-action cycle. Ann Surg 2015;262:1016-25.

29. Thanh NX, Chuck AW, Wasylak T, et al. An economic evaluation of the Enhanced Recovery After Surgery (ERAS) multisite implementation program for colorectal surgery in Alberta. Can 7 Surg 2016; 59:415-21.

30. Barton J, Bain C, Hennekens CH, et al. Characteristics of respondents and non-respondents to a mailed questionnaire. Am 7 Public Health 1980;70:823-5.

31. Kellerman SE, Herold J. Physician response to surveys: a review of the literature. Am F Prev Med 2001;20:61-7. 